\title{
NUMERICAL MODELS FOR THE PREDICTION OF ICEBERG DRIFT \\ (Abstract only)
}

by

\section{J. G. Napoleoni}

(Compagnie Française des Pétroles, 204, Rond-Point du Pont de Sèvres, 92516 Boulogne Billancourt Cedex, France)

\begin{abstract}
In order to avoid the risk of icebergs colliding with drilling vessels and installations in the Labrador Sea, it would be useful to predict iceberg drift. Relevant information on fluid dynamics is summarized, followed by a discussion of various drift models. After commenting on the numerical results obtained with these models, a method is proposed for analysing past trajectories of an iceberg in order to determine coefficients necessary for predicting its drift. The theoretical results are then compared with drift and sea-current and wind data obtained in the Labrador Sea. If accurate prediction of iceberg drift is to be achieved, reliable prediction of oceanic factors is just as important as a knowledge of iceberg characteristics. The techniques developed and tested in the Labrador Sea are helpful whether icebergs are considered as a problem or as a desirable resource.
\end{abstract}

